\title{
Modelling and Experimental Study on Active Energy-Regenerative Suspension Structure with Variable Universe Fuzzy PD Control
}

\author{
Jiang Liu, Xiaowei Li, Zhenghao Wang, and Ye Zhang \\ School of Automobile and Traffic, Qingdao University of Technology, Qingdao 266520, China \\ Correspondence should be addressed to Jiang Liu; zeh@163.com
}

Received 20 June 2016; Revised 29 August 2016; Accepted 4 October 2016

Academic Editor: Vadim V. Silberschmidt

Copyright (C) 2016 Jiang Liu et al. This is an open access article distributed under the Creative Commons Attribution License, which permits unrestricted use, distribution, and reproduction in any medium, provided the original work is properly cited.

\begin{abstract}
A novel electromagnetic active suspension with an energy-regenerative structure is proposed to solve the suspension's control consumption problem. For this new system, a 2-DOF quarter-car model is built, and dynamics performances are studied using the variable universe fuzzy theory and the PD control approach. A self-powered efficiency concept is defined to describe the regenerative structure's contribution to the whole control consumption, and its influent factors are also discussed. Simulations are carried out using software Matlab/Simulink, and experiments are conducted on the B-class road. The results demonstrate that the variable universe fuzzy control can recycle more than 18 percent vibration energy and provide over 11 percent power for the control demand. Furthermore, the new suspension system offers a smaller body acceleration and decreases dynamic tire deflection compared to the passive ones, so as to improve both the ride comfort and the safety.
\end{abstract}

\section{Introduction}

It has been proved by many scholars' studies that the active vehicle suspension technology can improve the vehicle dynamic performance [1-3], but it is still not widely applied in practice owing to its high cost on the energy consumption. Meanwhile the suspension vibration excited by the uneven road surfaces is usually wasted as thermal energy by the shock absorber. If the consumption energy could be reused properly, the suspension vibration is also a kind of resource. Therefore, many researches on these potential benefits have been carried out, theoretically and experimentally [4-6].

Suda and Shiiba firstly noticed the regenerative solution for the suspension control [7]. Then the energy feedback techniques, both the new structures design and the advanced control algorithm, have been well studied. Nakano et al. proposed a method based on a single electric actuator to analyze the balance between consumed and regenerative energy [8]. Nakano et al. developed an active suspension with the self-powered via linear DC motors, which can be used as an energy-regenerative damper through the actuator [9]. Kawamoto et al. proposed an electromechanical suspension (EMS) system, which consists of a ball screw mechanism via the DC motors [10]. Also, they discussed the nexus of the contour maps for the energy consumption and vibration isolation. For instance, Zhang et al. designed the active suspension and energy-regenerative controllers, respectively, based on the $H_{\infty}$ control, which are the same as the electromechanical suspension (EMS) system [11]. The EMS system indicated that the energy regeneration with a restriction strategy can be realized. Chen et al. proposed the electromagnetic damper which can absorb the vibration energy to improve the suspension dynamic performance [12]. Guo et al. proposed a hydraulic electromagnetic energyregenerative shock absorber (HESA), which can absorb the vibration energy harvest and improve the vehicle ride comfort and handling $[13,14]$. Although the above studies indicate that the energy-regenerative systems can obtain the electric energy via the considerable complex structures, the existing energy-regenerative suspension (ESS) systems have to increase the unsprung mass and change the original suspensions structure. Saito et al. converted the vibration energy to electric energy with an electrical suspension system which can offer quicker responses and higher operating accuracy 
than the hydraulic system [15]. Subsequently, some electromagnetic actuators (EA) have received attention for their easy energy regeneration, higher efficiency, quick response, and good controllability [16-19].

In last decades, many researchers applied some linear and nonlinear control methods to quarter-car models which were simple and preferred. In most cases, the energyregeneration efficiency is closely related to the control algorithm. The question is how to compromise the disunity between the accuracy and the efficiency such as $H_{\infty}$ and PID. Pan et al. used a composite $H_{\infty}$ adaptive fuzzy controller (CHAFC) on an uncertain nonlinear system to solve the fuzzy approximation problem $[20,21]$. The variable universe fuzzy (VUF) controller is regarded as a promising algorithm owing to its outstanding accusation-efficiency balance. Shan et al. developed an analog circuit of a VUF controller [22]. Wang et al. applied the VUF control to the hydropneumatic suspension and magnetic-rheology absorber (MRA) [23, 24]. Li et al. succeeded via the VUF controller based on conscious knowledge to simulate the model of the quadruple inverted pendulum [25]. It is noteworthy that Pan et al. proposed the novel VUF controllers with an adaptive control strategy through the Lyapunov synthesis [26, 27]. For instance, Liu et al. proposed a method of the VUF based on the two stage control rules and introduced it to the semiactive suspension (SAE) of the magneto rheological (MR) armored vehicle [28]. As a consequence, the method also can get an ideal performance of the vehicles control and effectively improve the vehicle ride comfort. However, the high performance of the control algorithm mentioned above is still difficult to solve the high energy consumption of the suspension and limited its wide application, especially in electric vehicles.

In this paper, a 2-DOF quarter-car model is built. Based on the dynamic model, three algorithms, such as the optimal control algorithm, fuzzy control algorithm, and variable universe fuzzy control algorithm, are designed. The influences on the control effects and the energy-regenerative effects choosing different road inputs and different control algorithms are analyzed, respectively. The simulation results show that different road inputs have similar control effects for LQG controller. The experiment results show that the performance of active energy-regeneration suspension system is highly dependent on the choice of algorithm employed, and the VUF control strategy exhibits an excellent integrated performance. But for the fuzzy controller and variable universe fuzzy controller, the worse the road condition is, the better the control effect of the body acceleration and dynamic tire deflection is. The energy-regenerative efficiency did not vary from road inputs in three controllers. The main studying contributions are (1) to propose a novel active energyregeneration suspension (AERS) system which can transform the electrical power efficiently; (2) to utilize VUF and PD theories for the AERS control; (3) to define a self-powered efficiency concept in order to describe the regenerative structures' contribution to the control consumption; (4) to do simulations and experiments so as to demonstrate the energyregenerative and the suspension control performances.

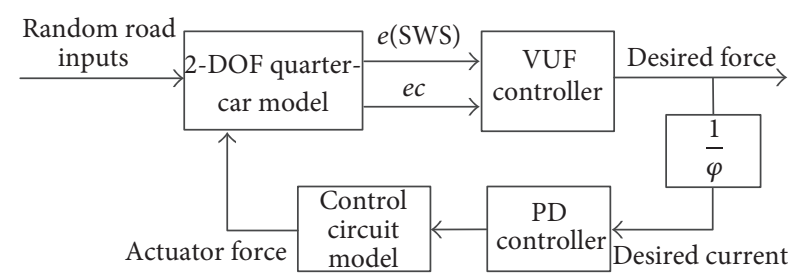

Figure 1: The VUF control schematic of the AERS.

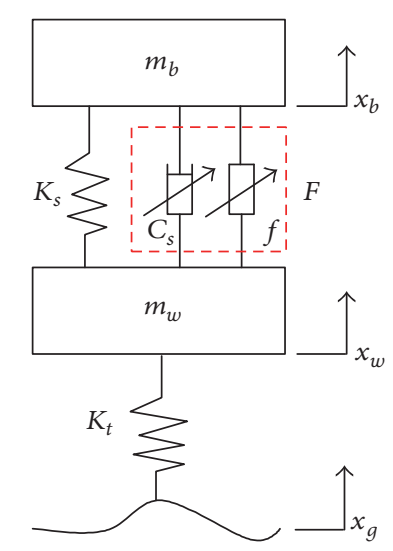

FIGURE 2: 2 DOF of the quarter-car model.

\section{A Novel Model of the AERS System}

2.1. Principle of Suspension Control. To propose a new control model for the active electromagnetic energy-regenerative suspension (AEERS), we firstly add a VUF controller and a simple PD controller to the traditional 2-DOF car model. The principle of the control theory is shown in Figure 1. One of the 2-DOF car model's output parameters, namely, the suspension working space (SWS), is taken as the inputs for VUF controller. That is to say, the parameters $e$ and $e c$ are, respectively, the deviation and its rate of the SWS. Then the VUF controller could offer a desired force or current for the PD controller and through the circuit model the motor's force would be fed back to the car model. $\varphi$ is the constant of the screw motor. Therefore, this control algorithm can ensure the consistency of the two forces, that is, the actual control force on the car model and the ideal control force from the VUF.

2.2. The 2-DOF Car Model. A quarter-car model is established to evaluate the dynamic performance and energy regeneration of AERS system, as shown in Figure 2. It is assumed that each of the four wheels has independent suspension to simulate the actions of an active vehicle suspension system, and, therefore, quarter-car models are used for many simulations of suspension system, where $m_{b}$ and $m_{w}$, respectively, denoted the sprung mass (the vehicle body) and unsprung mass (the wheels), which are considered as rigid body. $x_{b}$ and $x_{w}$, respectively, denoted the displacement of the sprung mass and unsprung mass, namely, the 2 degrees of freedom. $x_{g}$ is the road displacement. The tire is denoted by a linear spring. $K_{s}$ and $K_{t}$ represent the suspension and tire stiffness, respectively. Besides the actuator force $f$, 


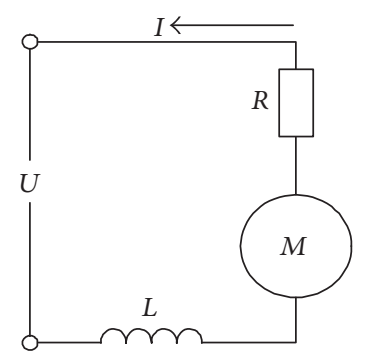

(a) Generator

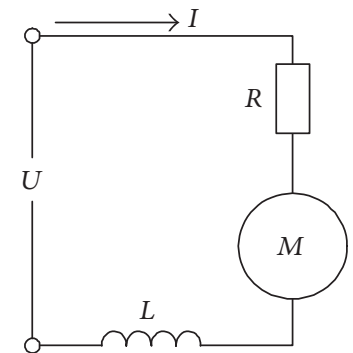

(b) Motor

FIGURE 3: Schematics of the circuit model.

the control force $F$ from the generator/motor and the ball screw assembly could also offer the suspension an adjustable damping coefficient $C_{s}$. So there is $F=-C_{s}\left(\dot{x}_{b}-\dot{x}_{w}\right)+f$.

From 2-DOF quarter-car model, the dynamic equations can be written as follows:

$$
\begin{aligned}
m_{b} \ddot{x}_{b} & =-K_{s}\left(x_{b}-x_{w}\right)+F \\
m_{w} \ddot{x}_{w} & =K_{s}\left(x_{b}-x_{w}\right)+K_{t}\left(x_{g}-x_{w}\right)-F .
\end{aligned}
$$

2.3. Random Road Input. The road profile input is a very important factor for a pavement vehicle's dynamic responses. It is usually regarded as a space-domain vibration motivation. The road roughness is assumed to be a Gaussian random process via shaping filters [29]. The road profile input for the quarter-car model can be described by the equation as follows:

$$
\dot{x}_{g}(t)=-2 \pi f_{0} x_{g}(t)+2 \pi n_{0} \sqrt{G_{0} v_{0}} \cdot \omega(t),
$$

where $f_{0}$ denotes the lower limiting frequency; $n_{0}$ is the reference spatial frequency and regarded as $0.1 \mathrm{~m}^{-1} ; G_{0}$ is the uneven road coefficient; $v_{0}$ represents the vehicle's velocity; $\omega(t)$ is a zero-mean Gaussian white noise.

2.4. Control Circuit Model. The actuator consisted of a ball screw for motion translation and a permanent magnetic brushless linear DC motor. The motor not only is for the active control but also functioned as an energy-regenerative generator. The circuit schematics for the two working patterns are shown in Figures 3(a) and 3(b) and, respectively, represented the circuit diagram as a generator or a motor. $U$ is the supply voltage of power source; $R$ and $L$ are the motor resistance and inductance, respectively; $I$ is the armature current.

The ideal actuator has the following characteristics:

$$
\begin{aligned}
E_{M} & =\varphi \dot{z} \\
F & =\varphi I,
\end{aligned}
$$

where $E_{M}$ is the electromotive force (EMF) of the motor; $\dot{z}$ is the axial velocity of the ball screw; $\varphi$ is the motor constant of the screw, $\varphi=k / l ; k$ is the motor constant; $l$ is the lead screw.
2.4.1. Circuit of the PD Control. From Figure 3(b), the circuit equation is described as follows:

$$
U=L \frac{d I}{d t}+R I+E_{M} .
$$

From this equation, we can know that the armature current $I$ would change with the controller voltage $U$.

By (4), when the geometric structure of the motor and the ball screw is certain, the active control force $F$ is a function of the armature current $I$.

According to (4), we can obtain the desired ideal current $I_{0}$ :

$$
I_{0}=\frac{F_{0}}{\varphi} .
$$

The current deviation is obtained as follows:

$$
e_{0}=I_{0}-I \text {. }
$$

The PD control voltage is written as follows:

$$
U=K_{P} e_{0}+K_{d} \frac{d e_{0}}{d t},
$$

where $I_{0}$ is the ideal current of the armature; $F_{0}$ is the ideal active control force; $e_{0}$ is the error of armature current; $K_{P}$ is the proportion coefficient of the $\mathrm{PD}$ controller; $K_{P}$ is the differential coefficient of the PD controller. follows:

Based on (3), (5), and (8), there is another equation as

$$
K_{P} e_{0}+K_{d} \frac{d e_{0}}{d t}-\varphi \dot{z}=L \frac{d I}{d t}+R I .
$$

Using (9) to Laplace transform obtains the following:

$$
I(s)=\left[\left(K_{P}+K_{d} s\right) e(s)-\varphi z(s) s\right] \cdot \frac{1}{L s+R},
$$

where $s$ is the Laplace operator.

Then we can get the PD controller schematic shown in Figure 4 .

2.4.2. Self-Powered Efficiency. According to Figure 3(a), the motor on the generator pattern would have a voltages balance written as follows:

$$
U_{c r}=E_{M}-U_{R}
$$




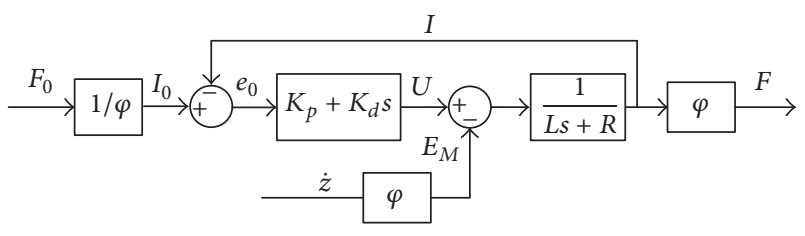

FIGURE 4: PD controller.

where $U_{c r}$ is the power supply voltage for the generator; $U_{R}$ is the internal resistance voltage.

Substituting the above expression to (11), the power supply voltage $U_{c r}$ is obtained as follows:

$$
U_{c r}=\varphi \dot{z}-I R=\varphi \dot{z}-\frac{F}{\varphi} \cdot R .
$$

On the other hand, the power supply voltage on the motor pattern $U_{c a}$, as shown in Figure 3(b), is written as follows:

$$
U_{c a}=E_{M}+E_{R}=\phi \dot{z}+\frac{F}{\phi} \cdot R .
$$

In order to evaluate the energy recycling efficiency for the suspension vibration, we assume $P_{r}$ as the power for the AERS and $P_{a}$ as the consumed power for active suspension. Therefore, we have

$$
\begin{aligned}
& P_{r}=U_{c r} \cdot I=F \dot{z}-F^{2} \cdot \frac{R}{\varphi^{2}} \\
& P_{a}=U_{c a} \cdot I=F \dot{z}+F^{2} \cdot \frac{R}{\varphi^{2}} .
\end{aligned}
$$

From (14), an equivalent damping coefficient $c_{e q}$ is proposed to describe the damping coefficient of the motor, which can be defined as follows:

$$
c_{e q}=\frac{\varphi^{2}}{R} .
$$

The definition indicates both the electric-magmatic properties and mechanism properties, illustrating the physical features of the AERS model. So (14) should be simplified as a 2-order function of the control force $F$, without the constant item:

$$
\begin{aligned}
& P_{r}=\dot{z} F-\frac{1}{c_{e q}} F^{2} \\
& P_{a}=\dot{z} F+\frac{1}{c_{e q}} F^{2} .
\end{aligned}
$$

Then we can define the ratio between the above two powers as the self-powered efficiency (SPE), symbolized as $\eta_{s}$. The mathematics equation is as follows:

$$
\eta_{s}=\frac{P_{r}}{P_{a}}= \begin{cases}0 & P_{r} \leq 0 \\ 1-\frac{2}{1+\dot{z} c_{e q} / F} & P_{r}>0,\end{cases}
$$

where $F$ and $\dot{z}$ both are algebraic values.
According to (15) and (17), $\eta_{s}$ is related to $c_{e q}$. The more the equivalent damping coefficient is, the better the self-powered efficiency can be achieved. Therefore, it is better to choose a linear motor with a larger motor constant $k$ or select a lower internal resistant with a certain motor constant $k$ or select a lower internal resistant with a certain motor constant value. Consequently, it can increase the damping coefficient and improve the ride performance.

After the motor structure is already designed or selected, $c_{e q}$ has a constant value. So the SPE is only related to the $\dot{z} / F$ ratio. It means that the SPE is determined by the suspension dynamics:

$$
\eta_{s}=1-\frac{2}{1+\dot{z} c_{e q} / F}=1-\frac{2}{1+E_{M} / U_{R}} .
$$

When $P_{r}>0$, (17) can be rewritten as (18) which concerns more the generator/motor structure. We defined the ratio between the motor electromotive force and the internal resistances voltage as the feedback energy coefficient (FEC), symbolized with $K$ :

$$
K=\frac{E_{M}}{U_{R}} .
$$

When $K=1$, the motor feedback energy (MFE) is totally converted into a dissipating thermal energy by the internal resistance. In this case, we have the AERS power $P_{r}=0$ and the SPE coefficient $\eta_{s}=0$.

When $K=0\left(U_{R}=0\right)$, the SPE coefficient $\eta_{s} \rightarrow 1$, the MFE is totally converted into the electrical energy, and the dissipation energy is zero.

\section{Variable Universe Fuzzy Controller Design}

3.1. Variables of Input and Output Fuzzification and Method to Resolve. The suspension working space (SWS) $\left(x_{b}-x_{w}\right)$ and the relative velocity $\left(\dot{x}_{b}-\dot{x}_{w}\right)$ between the unsprung mass and the sprung mass are regarded as the two input variables. Therefore, there are $e=x_{b}-x_{w}$ and $e c=\dot{x}_{b}-\dot{x}_{w}$. The desired force $F_{0}$ is used as the output variable of the controller.

All of the fuzzy domains for $F_{0}, e$, and $e c$ are set to be $[-1,1]$. The fuzzy language subset is donated as

$$
\{N B, N M, N S, Z O, P S, P M, P b\} \text {. }
$$

3.2. Fuzzy Control Rules. The fuzzy control is used in an external-loop controller, which does not depend on the accurate controlled model. It is decided on the basis of the control knowledge and experience, which can ensure the good robustness [30].

As shown in Figure 1, it is vital to analyze the motions of the quarter-car model. Firstly, we clarify the equilibrium position as the origin of the coordinate system and the direction position is specified according to the SAE standard.

When $x_{b}-x_{w}>0$, the suspension is in a stretching condition. If $\dot{x}_{b}-\dot{x}_{w}>0$, the tendency of the suspensions amplitude is increasing, so the output variable should be chosen at a larger negative value. On the other hand, if 


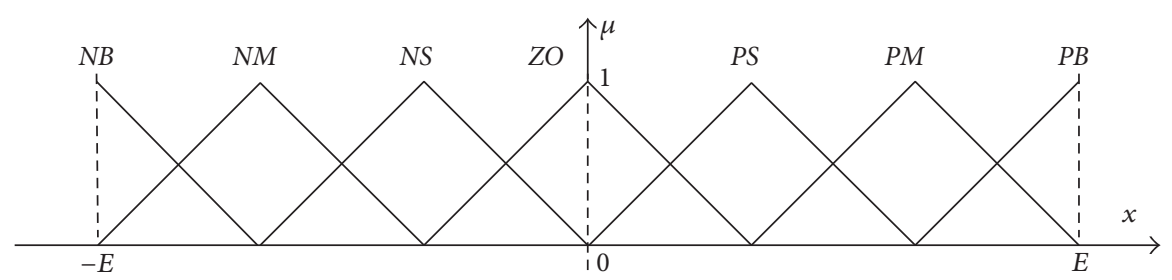

(a)

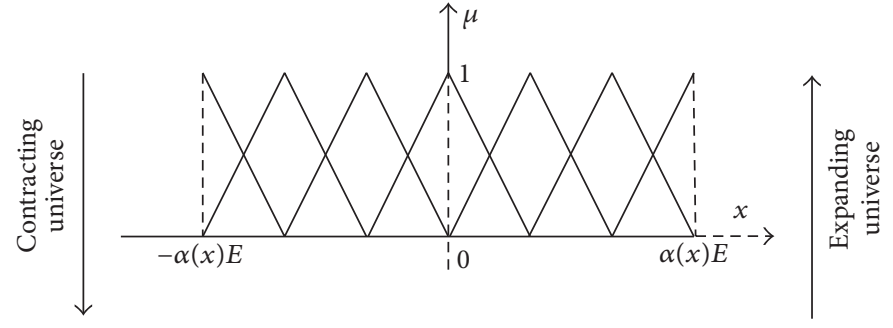

(b)

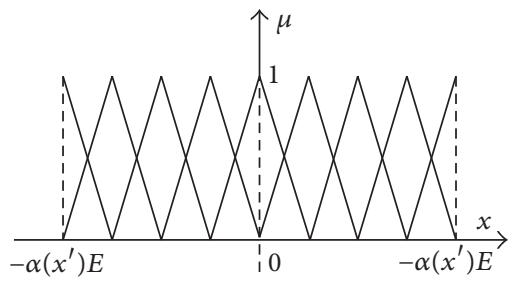

(c)

FIgURE 5: (a) The initial universe of its partition; (b) and (c) contracting-expending universes.

TABLE 1: Fuzzy control rules.

\begin{tabular}{|c|c|c|c|c|c|c|c|c|}
\hline \multirow{2}{*}{\multicolumn{2}{|c|}{$F_{0}$}} & \multicolumn{7}{|c|}{$e c$} \\
\hline & & $N B$ & $N M$ & $N S$ & $\mathrm{ZO}$ & $P S$ & $P M$ & $P B$ \\
\hline \multirow{7}{*}{$e$} & $N B$ & $P B$ & $P B$ & $P B$ & NS & NS & $N S$ & $N S$ \\
\hline & $N M$ & $P B$ & $P B$ & $P M$ & NS & $N M$ & $N M$ & $N S$ \\
\hline & NS & $P B$ & $P M$ & $P S$ & NS & $N S$ & $N M$ & $N M$ \\
\hline & $Z O$ & $P M$ & $P S$ & $Z O$ & $\mathrm{ZO}$ & $N S$ & $N M$ & $N M$ \\
\hline & $P S$ & $P S$ & $P M$ & $P M$ & $P S$ & $N M$ & $N M$ & $N B$ \\
\hline & $P M$ & $P S$ & $P M$ & $P B$ & $P S$ & $N M$ & $N B$ & $N B$ \\
\hline & $P B$ & $P M$ & $P M$ & $P B$ & $P S$ & $N B$ & $N B$ & $N B$ \\
\hline
\end{tabular}

$\dot{x}_{b}-\dot{x}_{w}<0$, the trend of the suspensions amplitude is dropping. Therefore, it is better to select a lower positive control value.

When $x_{b}-x_{w}<0$, the suspension is in compression condition. If $\dot{x}_{b}-\dot{x}_{w}>0$, the compression of the suspensions amplitude is dropping. Therefore it is better to select a smaller negative control value. If $\dot{x}_{b}-\dot{x}_{w}<0$, a larger number of a positive control value should be chosen in terms of the suspension amplitude compression increasing.

According to the principle of the above, we can build the fuzzy controller rules which are listed in Table 1.

3.3. Extension Factor. The VUF controller is an effective nonlinear control method. The basic structure of the VUF controller is briefly introduced in Section 3.3. In this paper, we select the variable universe fuzzy controller on AERS system control, which is described as a double input and a single output structure.

The universes $X_{i}=[-E, E](i=1,2)$ and $Y=[-U, U]$ would automatically adjust with the changing of variables $x_{i}$ and $y$, respectively, which offers a certain adaptive features. The relationships between the two variables and the initial universes are shown in Figure 5. $\mu$ is the membership function of fuzzy sets $Y$. They can also be described as follows:

$$
\begin{aligned}
X_{i}\left(x_{i}\right) & =\left[-a_{i}\left(x_{i}\right) E_{i}, a_{i}\left(x_{i}\right) E_{i}\right] \\
Y(y) & =[-\beta(y) U, \beta(y) U],
\end{aligned}
$$

where $\alpha_{i}\left(x_{i}\right)(i=1,2)$ and $\beta(y)$ represent the universe factors of the contraction-expansion. The universes $X_{i}$ and $Y$ were related to the initial universe.

Generally, there are 2 types extension factor, for example, a proportional type and an exponential type. The two practical contraction-expansion factors are given as follows:

$$
\begin{aligned}
& a(x)=\left(\frac{|x|}{E}\right)^{\tau}+\varepsilon, \quad \tau>0 \\
& a(x)=1-\lambda \exp \left(-k x^{2}\right), \quad \lambda \in(0,1), k>0,
\end{aligned}
$$

where $\varepsilon$ is a very small constant.

It is clear that these contraction-expansion factors include double inputs and single output with a similar form. Considering the relevance between the input variables and the practical vehicle parameters, we define them as follows:

$$
\begin{aligned}
& a(e)=1-0.5 \exp \left(-0.3 e^{2}\right) \\
& a(e c)=1-0.5 \exp \left(-0.3 e c^{2}\right) \\
& \beta(F)=1-0.5 \exp \left(-0.3 F^{2}\right) .
\end{aligned}
$$

\section{Simulations and Experiments}

4.1. Simulation Results and Analysis. In order to verify the effect of the controller and the superiority of the AERS system, three typical controller models are simulated in this study. In the process of the simulations, the dynamic response and performance of three vehicles are compared. 
TABLE 2: Main parameters of the simulation.

\begin{tabular}{lc}
\hline Parameter/unit & Value \\
\hline$m_{b}(\mathrm{~kg})$ & 130 \\
$K_{s}(\mathrm{~N} / \mathrm{m})$ & 20000 \\
$C_{s}(\mathrm{~N} \cdot \mathrm{s} / \mathrm{m})$ & 1000 \\
$v_{0}(\mathrm{~km} / \mathrm{h})$ & 20 \\
$L(\mathrm{H})$ & 0.3 \\
$\varphi(\mathrm{N} / \mathrm{A})$ & 90 \\
$m_{w}(\mathrm{~kg})$ & 15 \\
$K_{t}(\mathrm{~N} / \mathrm{m})$ & 200000 \\
$f_{0}(\mathrm{~Hz})$ & 0.1 \\
$n_{0}\left(\mathrm{~m}^{-1}\right)$ & 0.1 \\
$R(\Omega)$ & 10 \\
\hline
\end{tabular}

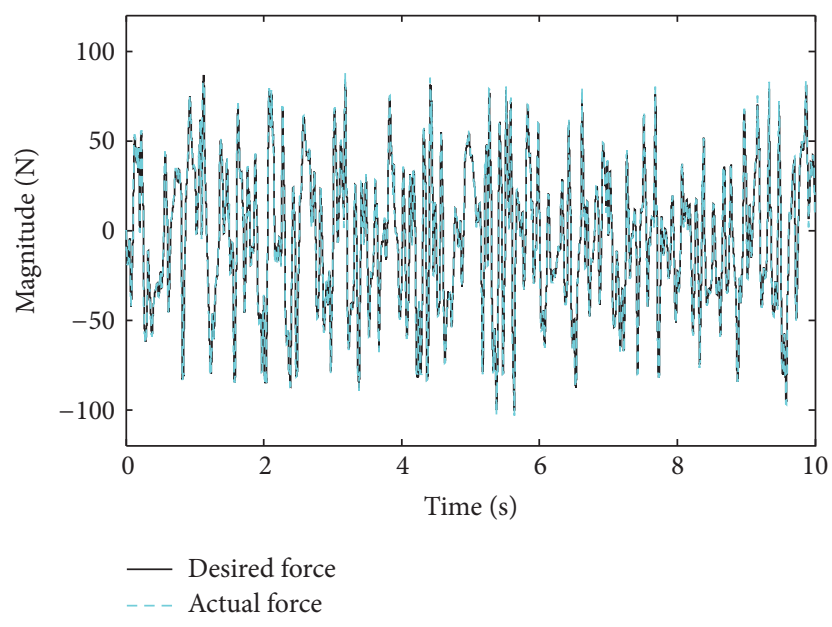

FIgURE 6: Control force.

These three vehicles are, respectively, with the proposed control algorithm, with the fuzzy controller, and without any controller. The performances can be evaluated by the body acceleration (BA), the suspension working space (SWS), and the dynamic tire deflection (DTD). All the simulation parameters for the VUF model are listed in Table 2.

Set the PD controller ratio coefficient $K_{P}=300$ and the differential coefficient $K_{d}=0.2$. Figure 6 shows the actuator force which is compared with the desired force on the B-class road.

From Figure 6, we can know that the actuator force is almost the same as the desired force. The root mean square (RMS) values of the actuator and the desired force are, respectively, $46.7 \mathrm{~N}$ and $46.58 \mathrm{~N}$, and the difference is merely $0.45 \%$. Obviously, the results show that the actuator force matches the desired force well.

Figures 7-9 demonstrate the time domain and frequency domain responses with the three typical suspension models, namely, passive one, with fuzzy controller, and with NUF controller, respectively. The BA, SWS, and DTD are, respectively, selected to evaluate the ride comfort and the stability performance.

Besides the above simulations, the RMS values for the three typical systems are listed in Tables 3 and 4,
TABLE 3: Suspension performance of B-class random road.

\begin{tabular}{lccc}
\hline $\begin{array}{l}\text { Performance } \\
\text { index }\end{array}$ & $\begin{array}{c}\text { Passive } \\
\text { suspension }\end{array}$ & Fuzzy control & $\begin{array}{c}\text { Variable } \\
\text { universe } \\
\text { fuzzy control }\end{array}$ \\
\hline $\mathrm{BA} /\left(\mathrm{m} / \mathrm{s}^{2}\right)$ & 0.51 & 0.46 & 0.42 \\
$\mathrm{SWS} / \mathrm{mm}$ & 1.96 & 1.97 & 1.96 \\
$\mathrm{DTD} / \mathrm{mm}$ & 0.38 & 0.37 & 0.36 \\
\hline
\end{tabular}

TABLE 4: Suspension performance of C-class random road.

\begin{tabular}{lccc}
\hline $\begin{array}{l}\text { Performance } \\
\text { index }\end{array}$ & $\begin{array}{c}\text { Passive } \\
\text { suspension }\end{array}$ & Fuzzy control & $\begin{array}{c}\text { Variable } \\
\text { universe } \\
\text { fuzzy control }\end{array}$ \\
\hline $\mathrm{BA} /\left(\mathrm{m} / \mathrm{s}^{2}\right)$ & 0.97 & 0.84 & 0.78 \\
$\mathrm{SWS} / \mathrm{mm}$ & 3.61 & 3.65 & 3.63 \\
$\mathrm{DTD} / \mathrm{mm}$ & 0.75 & 0.72 & 0.68 \\
\hline
\end{tabular}

which are achieved on the B-class road and C-class road, respectively.

Through the comparisons among the simulation data from Tables 3 and 4, it is clear that the VUF controller has the minor values of BA and DTD, which means the best comfort and safety. That is to say, the VUF controller is effective in guaranteeing the vehicle performances for the AERS system. If the ride comfort is regarded as a control target, the peak values of the BA and the DTD are reduced by $17.65 \%$ and $5.62 \%$ on the B-class road, compared with the passive one. Meanwhile on the C-class road the peak values are reduced by $19.59 \%$ and $9.33 \%$. Although the SWS value is a little more than that of the passive suspension, it is acceptable.

According to (17) and (18), the SPE and the energyregenerative efficiency (ERE) for the AERS system are calculated and the results are listed in Table 5. The calculations are carried out on different random roads, B-, C-, and D-class roads.

According to Table 5, all ERE values are more than 18 percent. It is very interesting that the rougher the road inputs are, the less the energy recycling ratio will get. The main reason would be due to the nonlinear factors and the hysteresis phenomena inevitably existing in most of the AERS structures. The AERS structure can also provide over 11 percent power for the suspension control in most of the regular road conditions, so the proposed system is also a good solution for the active control consumption.

4.2. Road Test and Analysis. Comparative tests between the active energy-regenerative suspension (AERS) and a passive suspension are carried out. The test car is a self-made electric vehicle and the test data acquisition systems are based on a NI test system, as shown in Figure 10. Tire stiffness is simulated by the four dampers. The acceleration and the dynamic deflection are obtained by using two acceleration sensors and displacement sensor from the sprung mass and unsprung mass, respectively. The relative velocity between the 


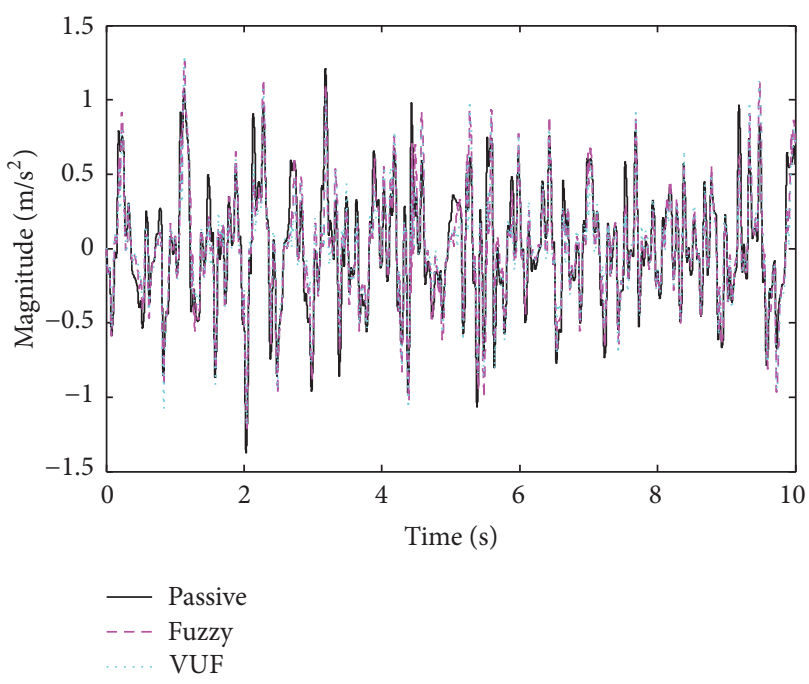

(a)

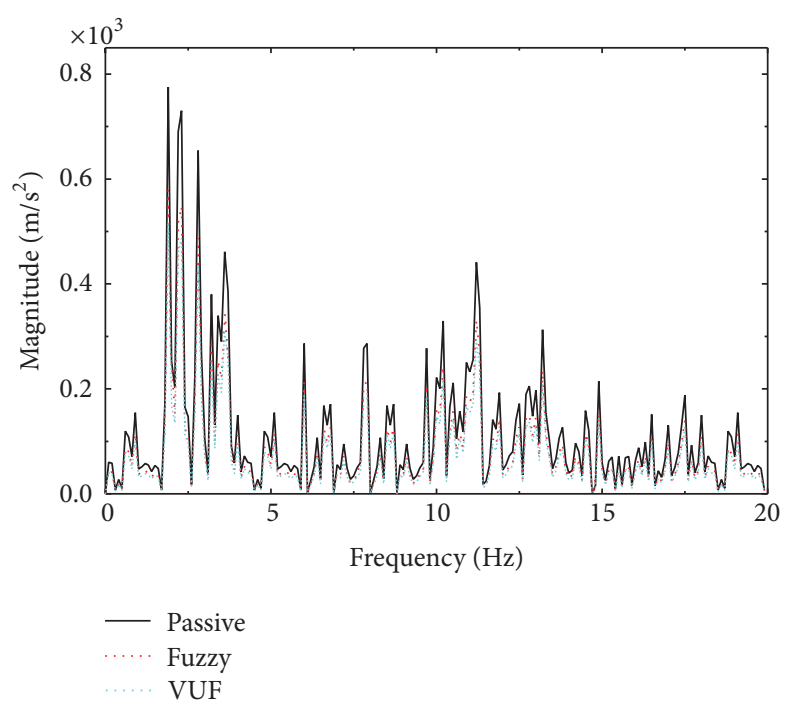

(b)

FIgURE 7: Body acceleration: (a) time domain and (b) frequency domain.

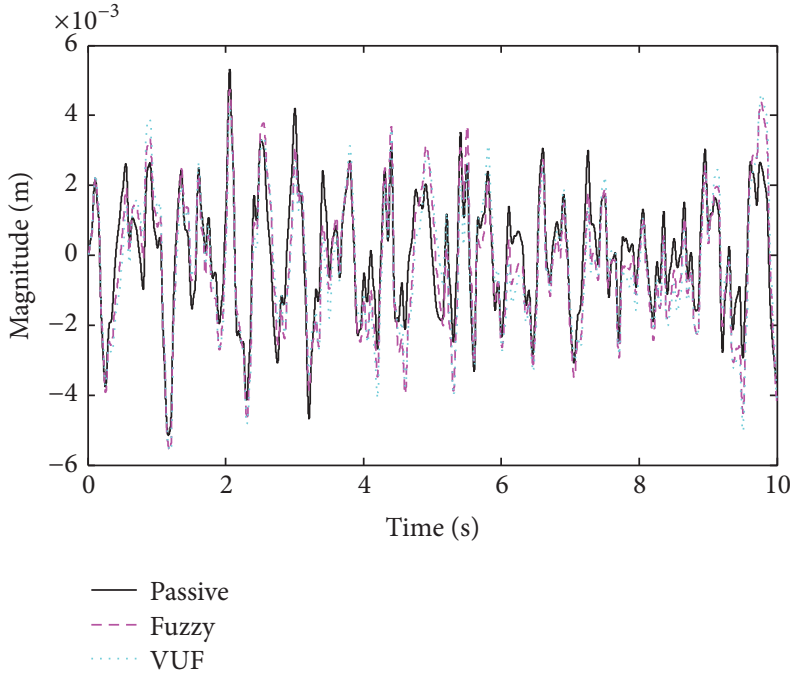

(a)

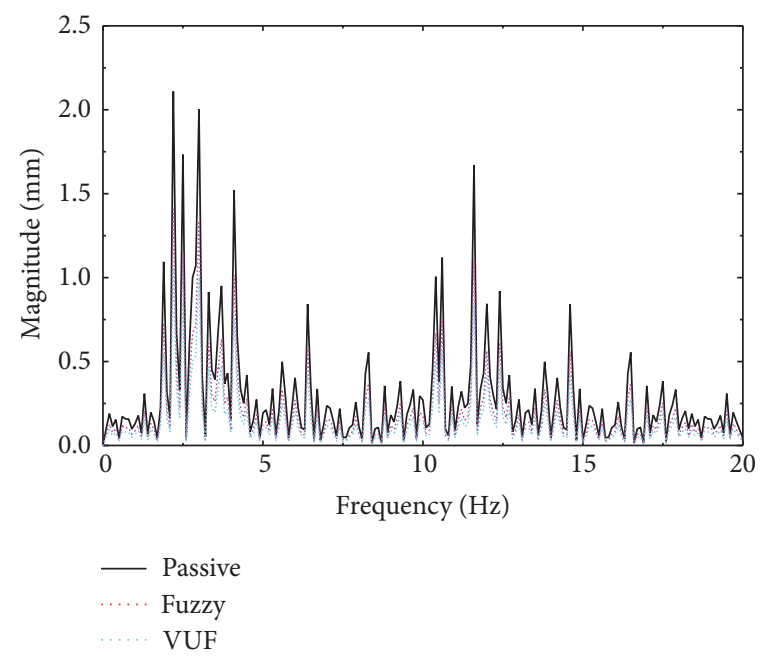

(b)

FIGURE 8: Suspension dynamic flexibility: (a) time domain and (b) frequency domain.

TABLE 5: Self-powered efficiency.

\begin{tabular}{lccccc}
\hline Random road & $P_{r}(W)$ & $P_{a}(W)$ & $P_{d}(W)$ & $\mathrm{ERE}^{*} / \%$ & $\mathrm{SPE} / \%$ \\
\hline B-class & 5.14 & 45.80 & 27.41 & 18.75 & 11.22 \\
C-class & 70.26 & 596.29 & 378.49 & 18.56 & 11.78 \\
D-class & 298.65 & 2595.31 & 1625.83 & 18.37 & 11.51 \\
\hline
\end{tabular}

${ }^{*}$ The energy-regenerative efficiency is the ratio of the ERP to DDP.

sprung mass and unsprung mass is calculated through the further differential processes.

The $\mathrm{B}$ random road is selected as the test input excitations, and the vehicle speed is $20 \mathrm{~km} / \mathrm{h}$. Limited by the test conditions, the test parameters are slightly different from the simulation parameters which are listed in Table 2, but their influences can be neglected for these performance analyses. The results of the road test are shown in Figures 11-13 and Table 6.

According to the experimental curves shown in Figures 11-13 and the RMS values in Table 6, the ride comfort is improved when the frequency is lower than the unsprung mass's resonance frequency. Also, the RMS value of the vertical body acceleration (BA) is reduced by $16.32 \%$, and the dynamic tire deflection (DTD) is reduced by $5.55 \%$. The results also show that the ride comfort for the active energyregenerative suspension is improved.

According to (16) and (17), the ERE and the SPE for the AERS system are calculated based on the experimental data. 


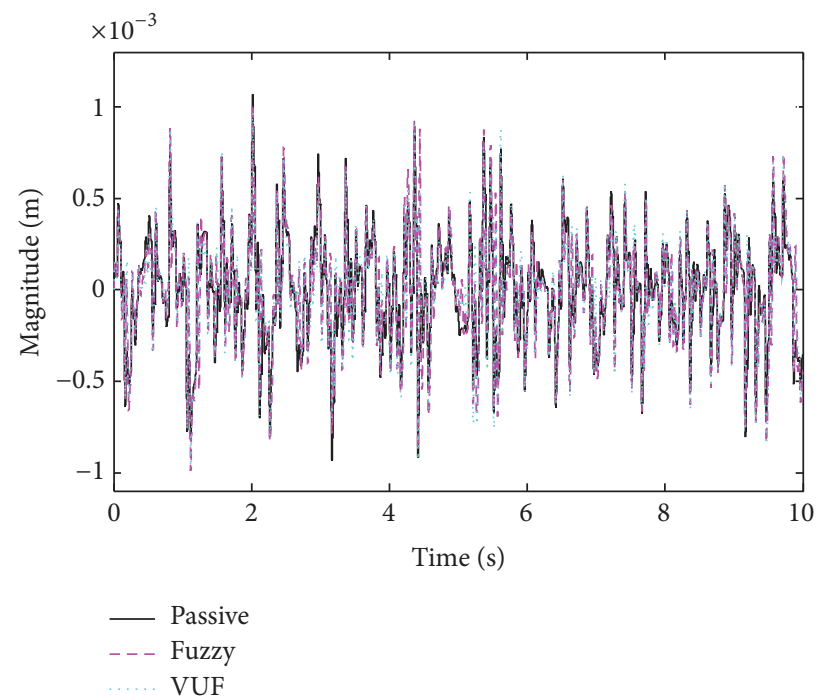

(a)

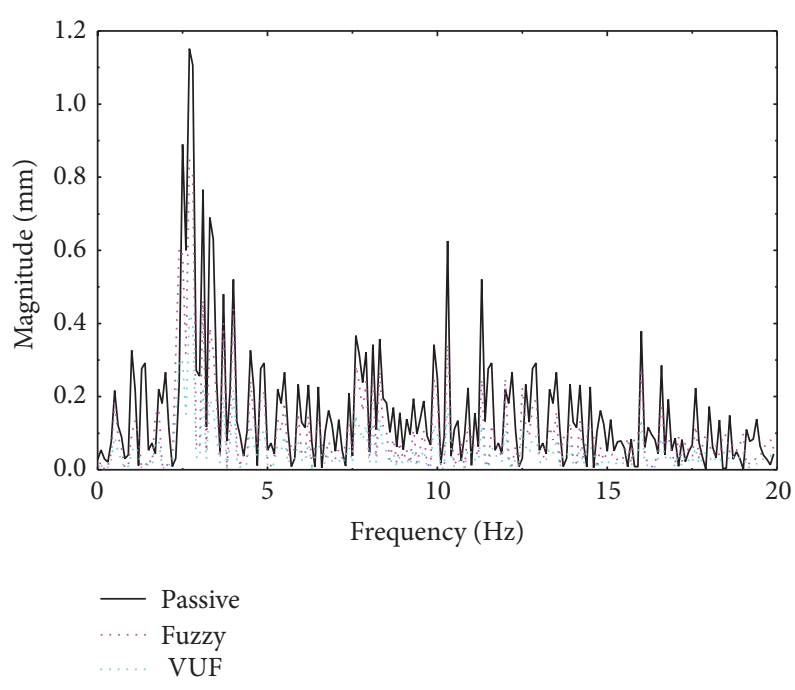

(b)

FIgURE 9: Tire dynamic displacement: (a) time domain and (b) frequency domain.

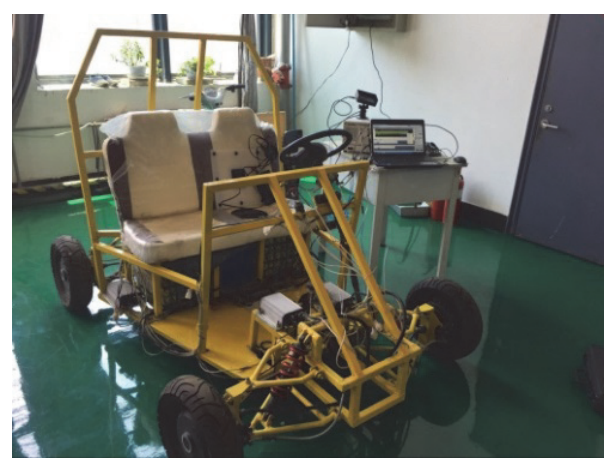

Figure 10: Road test.

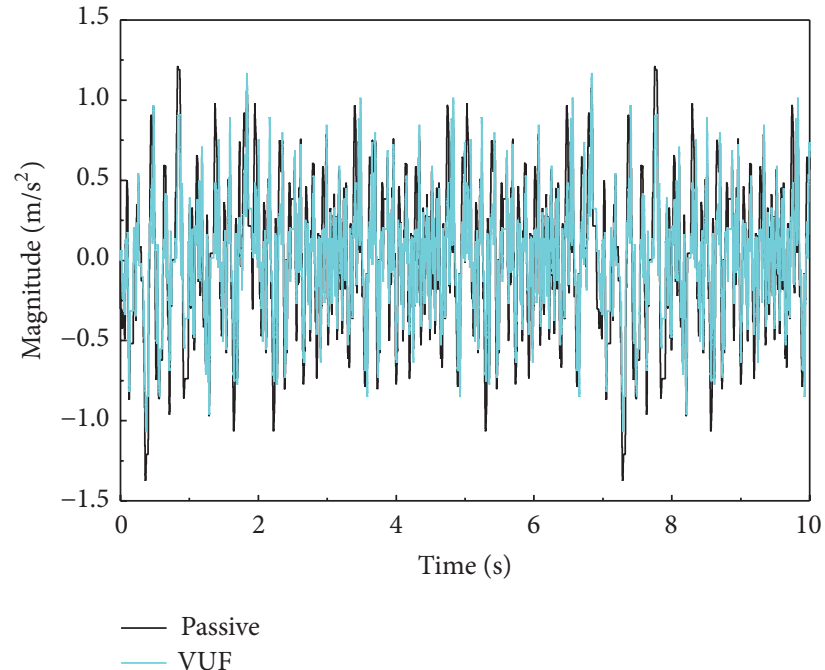

(a)

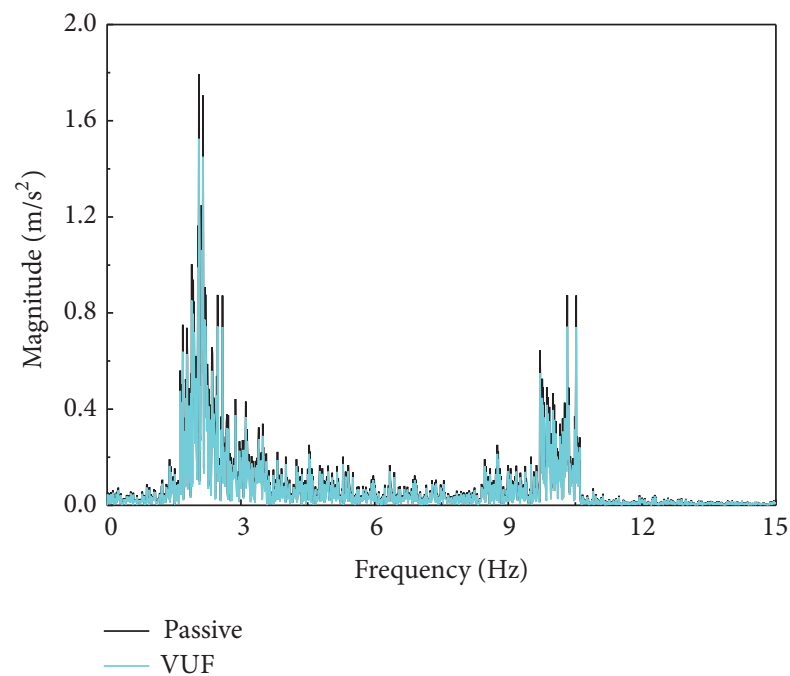

(b)

FIGURE 11: Experimental results of the body acceleration: (a) time domain and (b) frequency domain. 


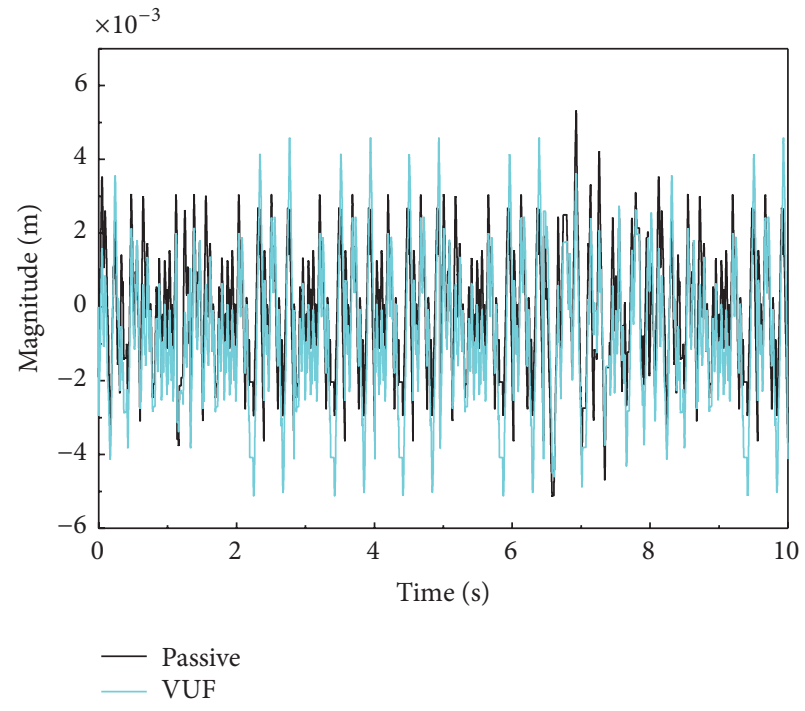

(a)

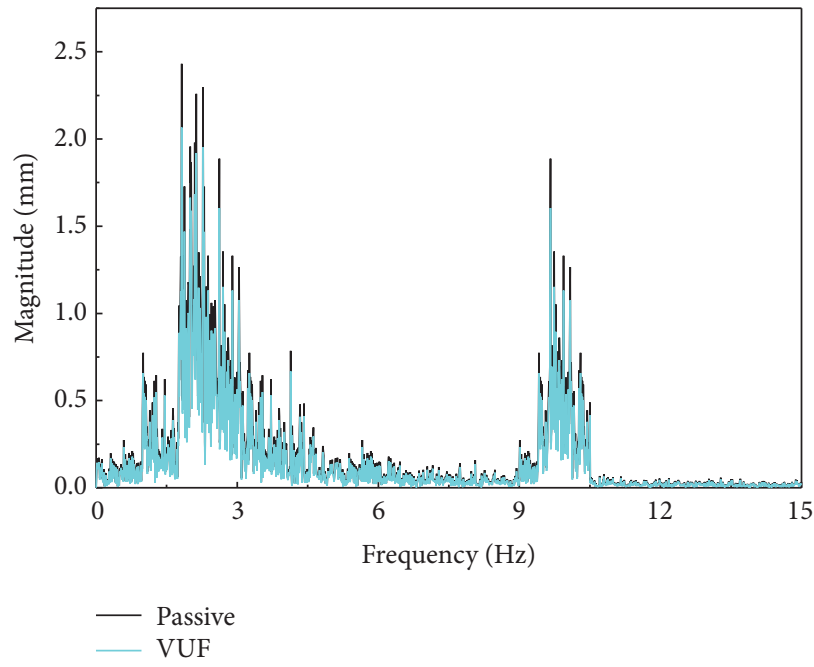

(b)

FIGURE 12: Experimental results of the suspension working space: (a) time domain and (b) frequency domain.

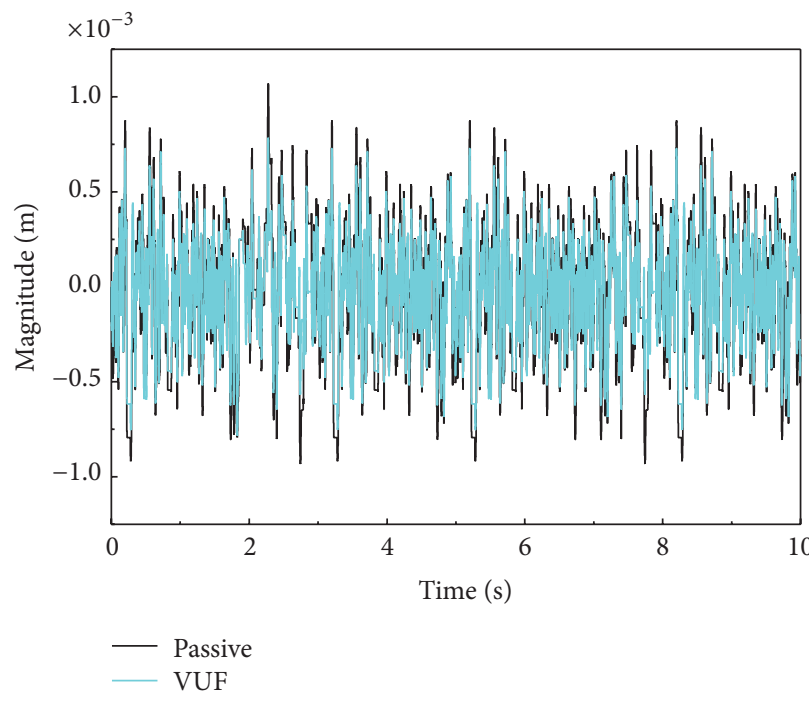

(a)

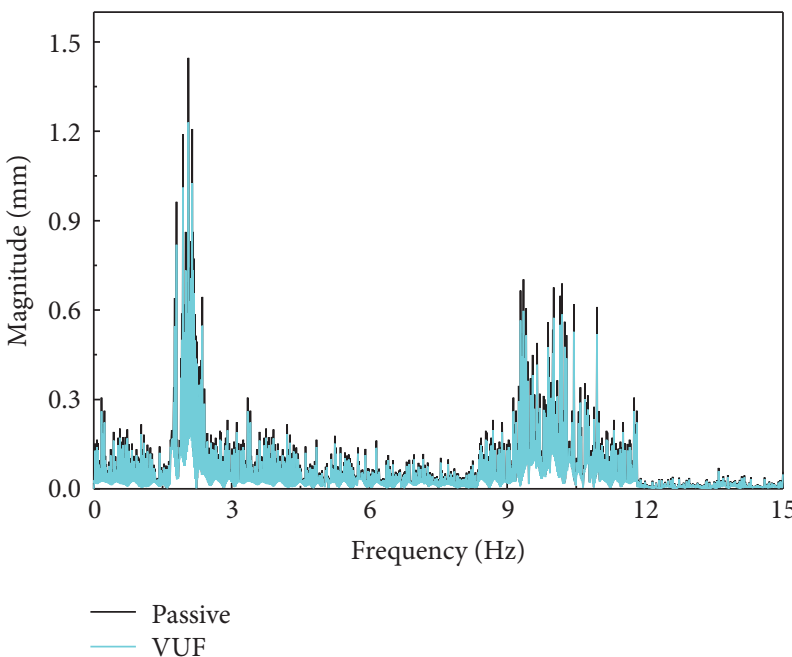

(b)

FIGURE 13: Experimental results of the tire dynamic displacement: (a) time domain and (b) frequency domain.

TABLE 6: Suspension performance of B-class random road.

\begin{tabular}{|c|c|c|}
\hline \multirow[b]{2}{*}{ Performance index } & \multicolumn{2}{|c|}{ RMS } \\
\hline & $\begin{array}{c}\text { Passive } \\
\text { suspension }\end{array}$ & $\begin{array}{c}\text { Variable } \\
\text { universe fuzzy } \\
\text { control }\end{array}$ \\
\hline $\mathrm{BA} /\left(\mathrm{m} / \mathrm{s}^{2}\right)$ & 0.49 & 0.41 \\
\hline SWS/mm & 1.94 & 1.94 \\
\hline $\mathrm{DTD} / \mathrm{mm}$ & 0.36 & 0.34 \\
\hline
\end{tabular}

The two test values are, respectively, $18.24 \%$ and $11.05 \%$, a little less (about 2\%) than the simulation values list in Table 5. The test results also validated the feasibility of the energy regeneration and self-powered ability.

\section{Conclusions}

In this paper, a novel AERS is proposed by integrating the adjustable shock absorber with a ball screw motor. The variable universe fuzzy control theory is applied to the active electromagnetic AERS. The RMS values of the vertical body acceleration and the dynamic tire deflection are significantly reduced on different random road inputs. With the energyregenerative $\mathrm{PD}$ control to the generator/motor circuit, the actuator force showed good consistency with the desired force.

A concept of the self-powered efficiency is proposed in order to evaluate the energy-regenerative structure's contribution to the suspension control. The study also demonstrated that the external resistance $R$ and the motor constant $k$ are the two key factors for the self-powered efficiency. 
The simulation results with B-, C-, and D-class road inputs showed that the energy-regenerative efficiency is over 18 percent and the self-power efficiency is over $11 \%$ for the ARS system with the VUF controller.

The experimental data on the B-class road is differed no more than $2 \%$ from the simulations. Both the test and calculating results indicated the feasibility of the energy regeneration as well as improvements on the ride comfort and driving safety.

\section{Competing Interests}

The authors declare that there is no conflict of interests regarding the publication of this paper.

\section{Acknowledgments}

This research was supported by the National Natural Science Foundation of China (Grant no. 51575288). The authors also express great gratitude for the help of the research team and the editors.

\section{References}

[1] K. Nakano, Y. Suda, M. Yamaguchi, and H. Kohno, "Application of combined type self-powered active suspensions to rubbertired vehicles," JSAE Annual Congress, vol. 6, pp. 19-22, 2003.

[2] P. Hsu, "Power recovery property of electrical active suspension systems," in Proceedings of the 31st IEEE Conference Energy Conversion Engineering, vol. 3, pp. 1899-1904, 1996.

[3] L. Zuo and P.-S. Zhang, "Energy harvesting, ride comfort, and road handling of regenerative vehicle suspensions," Journal of Vibration \& Acoustics, vol. 135, no. 1, Article ID 011002, pp. 1-8, 2013.

[4] D. Karnopp, "Power requirements for traversing uneven roadways," Vehicle System Dynamics, vol. 7, no. 3, pp. 135-152, 1978.

[5] S. A. Velinsky and R. A. White, "Vehicle energy dissipation due to road roughness," Vehicle System Dynamics, vol. 9, no. 6, pp. 359-384, 1980.

[6] L. Segel and X. P. Lu, "Vehicular resistance to motion as influenced by road roughness and highway alignment," Australian Road Research, vol. 12, no. 4, pp. 211-222, 1982.

[7] Y. Suda and T. Shiiba, "A new hybrid suspension system with active control and energy regeneration," Vehicle System Dynamics, vol. 25, pp. 641-654, 1996.

[8] K. Nakano, Y. Suda, and S. Nakadai, "Self-powered active vibration control using a single electric actuator," Journal of Sound and Vibration, vol. 260, no. 2, pp. 213-235, 2003.

[9] K. Nakano, Y. Suda, and S. Nakadai, "Self-powered active vibration control using continuous control input," JSME International Journal, Series C: Mechanical Systems, Machine Elements and Manufacturing, vol. 43, no. 3, pp. 726-731, 2000.

[10] Y. Kawamoto, Y. Suda, H. Inoue, and T. Kondo, "Modeling of electromagnetic damper for automobile suspension," Journal of System Design and Dynamics, vol. 1, no. 3, pp. 524-535, 2007.

[11] G. Zhang, J. Y. Cao, and F. Yu, "Design of active and energy-regenerative controllers for DC-motor-based suspension," Mechatronics, vol. 22, no. 8, pp. 1124-1134, 2012.

[12] L. Chen, D. Shi, R. Wang, and H. Zhou, "Energy conservation analysis and control of hybrid active semiactive suspension with three regulating damping levels," Shock and Vibration, vol. 2016, Article ID 6196542, 14 pages, 2016.

[13] Z. Fang, X. Guo, L. Xu, and H. Zhang, "An optimal algorithm for energy recovery of hydraulic electromagnetic energyregenerative shock absorber," Applied Mathematics \& Information Sciences, vol. 7, no. 6, pp. 2207-2214, 2013.

[14] R. L. Teixeira, F. P. L. Neto, and J. F. Ribeiro, "Modelling and experimental investigation of an active damper," Shock and Vibration, vol. 13, no. 4-5, pp. 343-354, 2006.

[15] T. Saito, Y. Sumino, and S. Kawano, "Research on energy conversion of mechanical vibration," in Proceedings of the Dynamics and Design Conference B, vol. 93, pp. 105-108, 1993.

[16] Y. Suda, K. Suematsu, K. Nakano, and T. Shiiba, "Study on electromagnetic suspension for automobilessimulation and experiments of performance," in Proceedings of the 5th International Symposium on Advanced Vehicle Control, pp. 699-704, Ann Arbor, Mich, USA, 2000.

[17] K. E. Graves, P. G. Iovenitti, and D. Toncich, "Electromagnetic regenerative damping in vehicle suspension systems," International Journal of Vehicle Design, vol. 24, no. 2-3, pp. 182-197, 2000.

[18] R. B. Goldner, P. Zerigian, and J. R. Hull, "A preliminary study of energy recovery in vehicles by using regenerative magnetic shock absorbers," SAE Paper 2001-01-2071, 2001.

[19] Y. Okada and H. Harada, "Regenerative control of active vibration damper and suspension systems," in Proceedings of the 35th IEEE Conference on Decision and Control, vol. 4, pp. 47154720, 1996.

[20] Y. P. Pan, Y. Zhou, T. R. Sun, and M. J. Er, "Composite adaptive fuzzy tracking control of uncertain nonlinear systems," Neurocomputing, vol. 99, no. 10, pp. 15-24, 2013.

[21] Y. P. Pan, M. J. Er, L. Pan, and H. Y. Yu, "Composite learning from model reference adaptive fuzzy control," in Proceedings of the International Conference on Fuzzy Theory and Its Applications (iFUZZY '15), pp. 91-96, IEEE, Yilan, Taiwan, November 2015.

[22] W. Shan, Y. Ma, R. W. Newcomb, and D. Jin, "Analog circuit implementation of a variable universe adaptive fuzzy logic controller," IEEE Transactions on Circuits and Systems II: Express Briefs, vol. 55, no. 10, pp. 976-980, 2008.

[23] D.-L. Wang, L. Gu, and G.-X. Ma, "Simulation analysis and experimental research on the variable universe fuzzy control of hydro-pneumatic suspension," Transaction of Beijing Institute of Technology, vol. 29, no. 4, pp. 314-317, 2009.

[24] Q. D. Wang, Q. Wang, and W. W. Chen, "Simulation analysis and experimental research on the variable universe fuzzy control of hydro-pneumatic suspension," Journal of Vibration Engineering, vol. 22, no. 5, pp. 512-518, 2009.

[25] H. X. Li, Z. H. Miao, and J. Y. Wang, "Variable universe stable adaptive fuzzy control of a nonlinear system," Computers and Mathematics with Applications, vol. 44, no. 5, pp. 799-815, 2002.

[26] Y. P. Pan and M. J. Er, "Enhanced adaptive fuzzy control with optimal approximation error convergence," IEEE Transactions on Fuzzy Systems, vol. 21, no. 6, pp. 1123-1132, 2013.

[27] Y. Pan, M. J. Er, D. Huang, and Q. Wang, "Adaptive fuzzy control with guaranteed convergence of optimal approximation error," IEEE Transactions on Fuzzy Systems, vol. 19, no. 5, pp. 807-818, 2011.

[28] F. Liu, Y. N. Li, and L. Zheng, "Variable universe fuzzy control for the magneto-rheological semi-active suspension in armored vehicles," Automotive Engineering, vol. 35, no. 8, pp. 735-739, 2013. 
[29] L. Soria, B. Peeters, and J. Anthonis, "Operational modal analysis and the performance assessment of vehicle suspension systems," Shock and Vibration, vol. 19, no. 5, pp. 1099-1113, 2012.

[30] D. H. Shi, L. Chen, R. C. Wang, H. Jiang, and Y. J. Shen, “Design and experiment study of a semi-active energy-regenerative suspension system," Smart Materials and Structures, vol. 24, no. 1, Article ID 015001, 2015. 


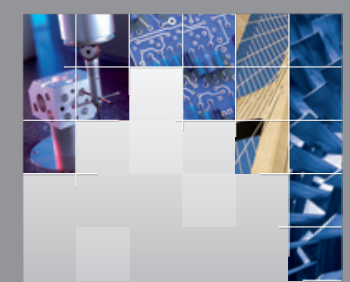

\section{Enfincering}
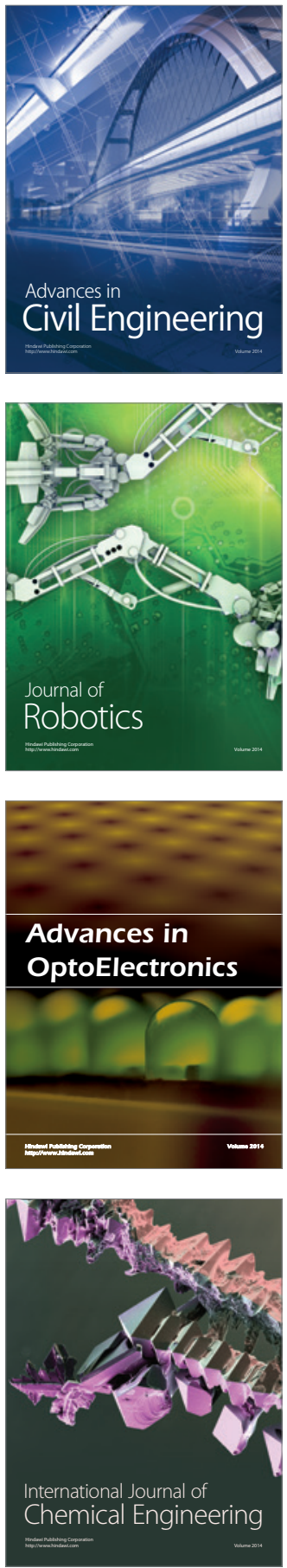

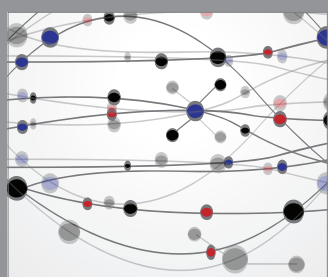

The Scientific World Journal

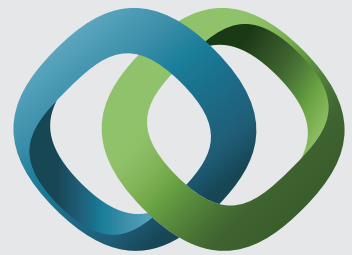

\section{Hindawi}

Submit your manuscripts at

http://www.hindawi.com
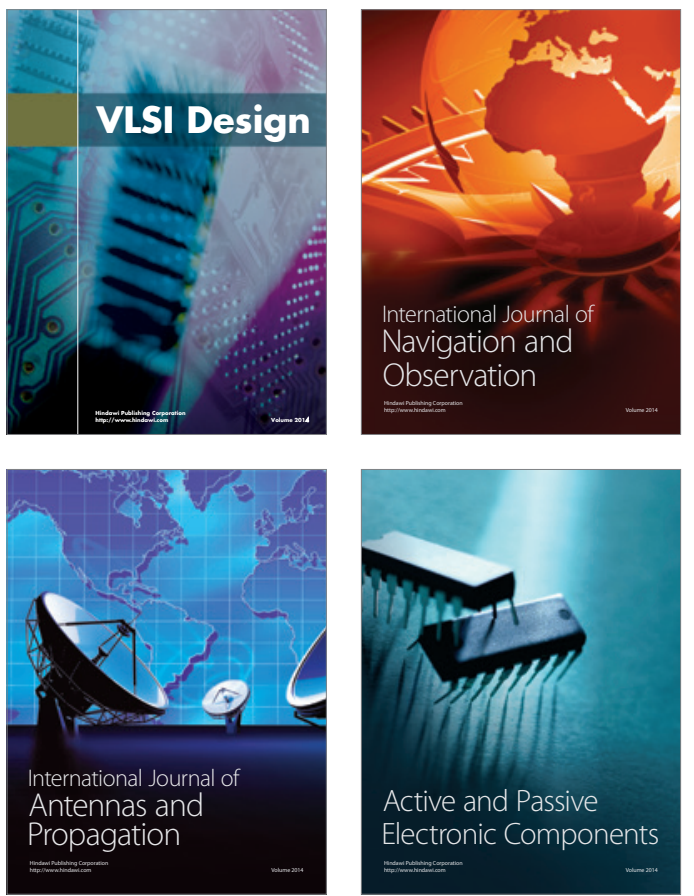
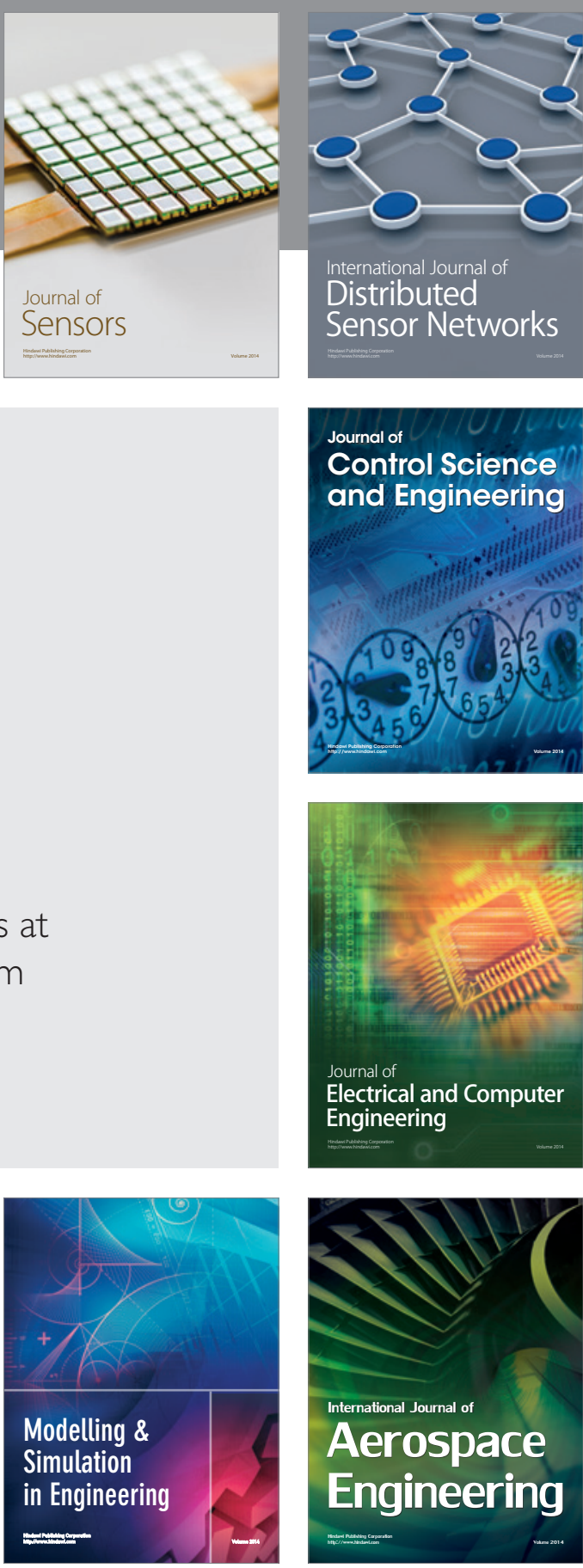

International Journal of

Distributed

Sensor Networks

Journal of

Control Science

and Engineering
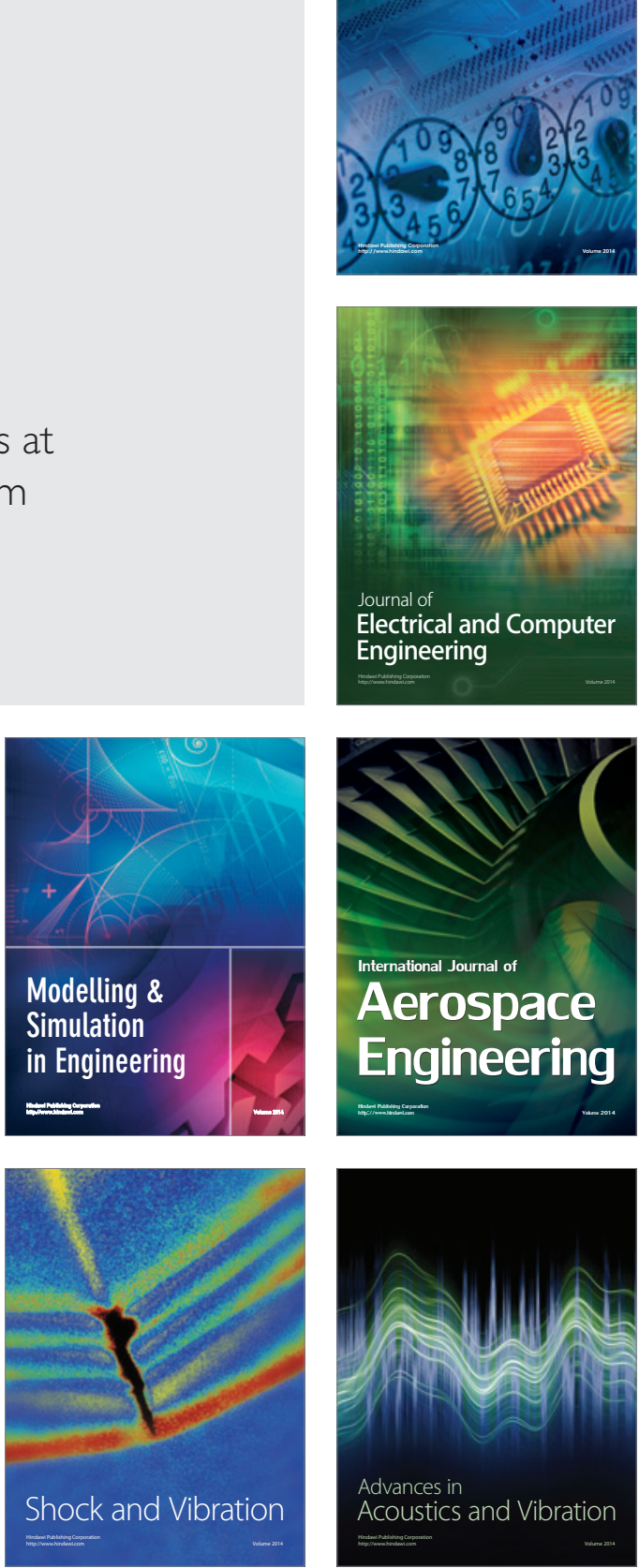